\title{
Journal of Pulmonary \& Respiratory Medicine
}

\section{Heterotopic Ossification after Lung Transplantation}

Stephan Keusch ${ }^{* 1}$ and Christian Benden ${ }^{2}$

${ }^{1}$ Division of Pulmonary Medicine, Zürcher Höhenklinik Wald, Switzerland

${ }^{2}$ Division of Pulmonary Medicine, Lung Transplant Unit, University Hospital Zurich, Switzerland

*Corresponding author: Stephan Keusch, Division of Pulmonary Medicine, Zürcher Höhenklinik Wald, Faltigbergstrasse 7, 8636 Wald, Switzerland, Tel: + +41552566830; Fax: ++41552566899; E-mail: postfach@keusch.biz

Received date: Jan 12, 2015, Accepted date: Jan 16, 2015, Published date: Jan 18, 2015

Copyright: (C) 2015 Keusch S, et al. This is an open-access article distributed under the terms of the Creative Commons Attribution License, which permits unrestricted use, distribution, and reproduction in any medium, provided the original author and source are credited.

Keywords: Lung transplantation; Heterotopic ossification

\section{Image Article}

A 40-year-old man who underwent lung transplantation for alpha-1-antitrypsine deficient emphysema showed in an abdominal x-ray, performed for the clinical suspicion of coprostasis, an unclear bone formation in the pelvis. He reported no complaints and clinical examination showed no tenderness, movement limitation or neurological deficits. In the computer tomography of the pelvis, surprisingly extraskeletal, heterotopic ossification of the gluteus minimus muscle of both sides were detected. No known risk factors for this pathology such as trauma, surgery, neurological or thermal injuries, or prolongued immobilization after transplantation could be established. It remains unclear if transplantation with start of triple immunosuppression or other unknown factors triggered this uncommon complication. In literature a case series $(n=5)$ on heterotopic bone formation after transplantation (orthotopic liver and lung) [1] and a single case-report after lung transplantation [2] have been reported. Established treatment options are surgical excision or radiotherapy if symptoms are burdensome necessitating an intervention.
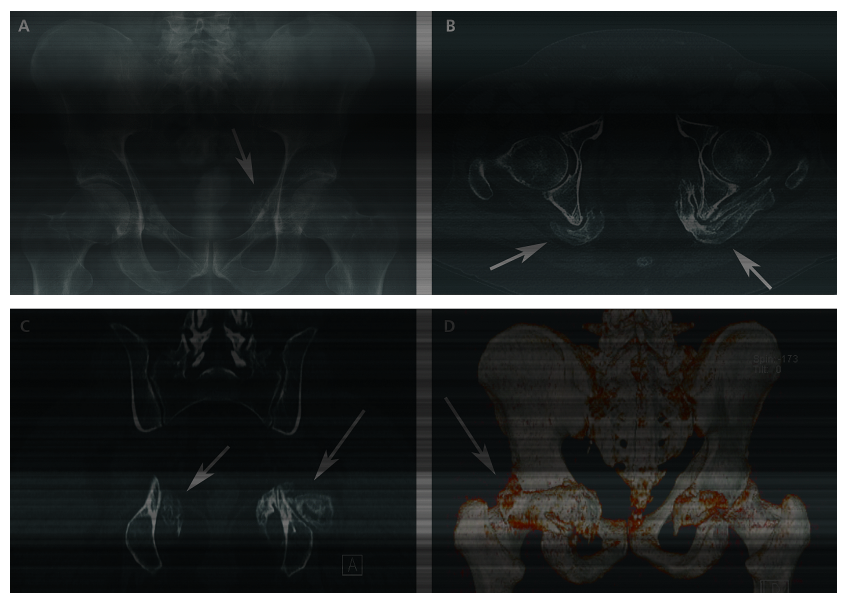

Figure: Heterotopic ossification of the pelvis.

Arrows mark the extraskeletal bone formation in the gluteus minimus muscle on both sides. Panel A: axial view, Panel B: coronal view, Panel C and D: sagittal view.

\section{References}

1. Munin MC, Balu G, Sotereanos DG (1995) Elbow complications after organ transplantation. Case reports. American journal of physical medicine \& rehabilitation 74: 67-72.

2. Schulze M, Lobenhoffer HP (1997) Heterotopic ossifications of 5 large body joints after 105 days of intensive care with 72 days of artificial ventilation. Der Unfallchirurg 100: 839-844. 